ISSN $0819-2642$

ISBN 9780734037299

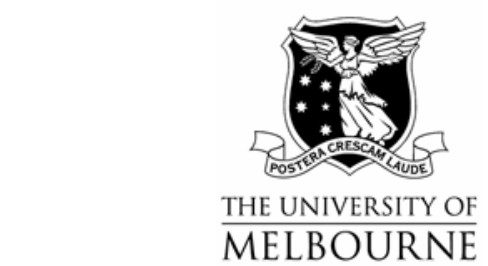

THE UNIVERSITY OF MELBOURNE

DEPARTMENT OF ECONOMICS

RESEARCH PAPER NUMBER 1019

December 2007

Between The Rock and a Hard Place: Regime Switching in the Relationship Between Short-Term Interest Rates and Equity Returns in the UK

by

Òlan T. Henry

Department of Economics

The University of Melbourne

Melbourne Victoria 3010

Australia. 


\title{
Between The Rock and a Hard Place: Regime Switching in the Relationship Between Short-Term Interest Rates and Equity Returns in the $\mathrm{UK}^{*}$
}

\author{
Ólan T. Henry \\ Department of Economics, \\ The University of Melbourne, \\ Victoria 3010, \\ Australia. \\ oth@unimelb.edu.au.
}

December $4^{t h}, 2007$

\begin{abstract}
We examine the relationship between short term interest rates and UK equity returns using a two regime Markov Switching EGARCH model. We find one high-return, low variance regime in which the conditional variance of equity returns responds persistently but symmetrically to equity return innovations. In the other, low-mean, highvariance, regime there is evidence that equity volatility responds asymmetrically and without persistence to shocks to equity returns. There is evidence of a regime dependent relationship between shorter maturity interest rate differentials and equity return volatility. Furthermore, there is evidence that events in the money markets influence the probability of transition across regimes.
\end{abstract}

Keywords: Regime switching; Time varying transition probabilities; News impact surfaces; Asymmetric volatility; Interest Rate Spreads.

J.E.L. Codes: G0, C5

${ }^{*}$ This paper was funded by the Australian Research Council under the Discovery Project Scheme, grant number DP0664286. The research was completed while the author visited the University of Cambridge. I am very grateful for the hospitality of the staff of Clare Hall and the Cambridge Endowment for Research in Finance. Discussions with Michael McKenzie, Mardi Dungey and Nilss Olekalns contributed greatly to the development of this paper. Any remaining errors and/or ommissions are the author's sole responsibility. 


\section{Introduction}

Under the dividend discount approach to equity pricing of Gordon (1962), and the dynamic counterpart of Campbell and Shiller (1988), the price of a share in equilibrium is determined by the discounted value of the expected cash flows accruing to the share. Campbell and Ammer (1993) decompose the variance of unexpected excess returns implied by the dividend discount model into three factors, news about future dividends, news about future interest rates, and news about future excess returns. These models predict that fluctuations to interest rates should cause equity prices to move and may also result in changes to the variance of equity returns.

In general, there are two major sources of interest rate fluctuations, those arising from changes in monetary policy and those arising from other, possibly extreme, events in the money markets.

On the one hand, over the last two decades there has been increased use of short term interest rates rather than measures of the money supply as intermediate targets for monetary policy. Any potential change in the policy rate is the focus of much attention from academics and practioners, as arbitrage will ensure that a change in the policy rate will affect all other traded interest rates in the economy. Any change in the stance of monetary policy may impact on share prices along a number of alternative channels. One possible channel is via the funding costs of a leveraged firm. Any change in the policy rate will change debt funding costs and consequently may impact on the profitability of the firm and its ability to pay dividends. Secondly, any change in the policy rate may affect the opportunity cost of equity investments, again impacting on share prices. Thirdly, changes in the policy rate may impact upon the level of real activity in economy in the short to medium term, and this may impact upon the value of equities by influencing the value of expected future cash flows. ${ }^{1}$

There is substantial empirical evidence to suggest that changes in monetary policy actually affect equity markets. Pearce and Roley (1985) find changes to monetary policy are significant determinants of movements in stock prices. Bernanke and Blinder (1992), Bernanke and Kuttner (2005) and Chen (2007), inter alia, all provide evidence that changes to monetary policy in the US impact on US equity values. Bredin, Hyde, Nitzsche and O'Reilly (2007) study the impact of domestic monetary shocks on UK stock returns.

On the other hand, there is also the possiblity that unexpected events in the interest rate markets will impact upon equity returns. Events such as the Russian debt crisis and the subsequent collapse of Long Term Capital Management in 1998, (see Jorion 2000 inter alia), or the sub-prime mortgage

\footnotetext{
${ }^{1}$ For further discussion of the impact of monetary policy on stock returns see Sellin (2001) or Bernanke and Kuttner (2005), inter alia.
} 
crisis of 2007 are good examples of such shocks. Leveraged firms that finance their activities through short-term arrangements may experience periods of high volatility when conditions in the debt markets make refinancing uncertain. This is particularly true for firms that finance long-term illiquid assets with short term borrowing, implicitly assuming that sufficient liquidity will always be available to refinance their activities.

The aim of this paper is to seek evidence that events in the money markets impact on equity returns and volatility. Given the widespread evidence of asymmetry in equity returns, (see Glosten Jaganathan and Runkle 1993, Engle and Ng 1993, Henstchel 1995 and Baekert and Wu 2000 inter alia) positive and negative interest rate innovations may have markedly different impacts on the mean and/or variance of equity returns. A second aim of this paper is to seek evidence of periods of high volatility in equity returns and further to examine whether these periods are associated with events in the money markets in a statistically significant fashion. Deuker (1997), Lunde and Timmerman (2004), Bae, Kim and Nelson (2007) and Chen (2007) inter alia all find evidence of regime switching in equity returns. A common finding in these papers is that equity returns display two regimes, a high-mean, low variance regime and a low-mean high variance regime. However, from an econometric point of view, it is not feasible to separate the first and second aims of this paper. Standard asset pricing models tell us that the riskiness of an asset is important in determining the true value of that asset. Optimal inference about the conditional mean of the asset return, requires that the conditional second moment be correctly specified. Consequently, in seeking to determine whether equity returns are influenced by events in short term money markets, and/or whether equity returns display infrequent intervals of high volatility, it is necessary to allow for both possibilities. Omission of the former possibility may lead to unreliable inference about the latter and vice-versa. Furthermore, given the widespread evidence of asymmetry in stock volatility, a standard symmetric regime-switching GARCH may very well fail to provide an adequate conditional characteristion of equity return dynamics.

The approach followed in this paper is to allow for two regimes in asset returns. Our full model characterises the within regime conditional variance as an exponential GARCH process. This allows us to encompass both types of innovation to volatility, that is, we allow for switching between regimes and time variation and asymmetry in the conditional variance within regime. However our model also allows for regime dependence in the impact, persistence and asymmetric response to shocks to equity volatility.

Our results suggest that there are two regimes in UK equity returns, a high-mean, low-variance regime and a low-mean high-variance regime. The evidence also suggests that shorter maturity interbank interest rate differentials are significant, regime dependent, determinants of the volatility of UK equity returns. Furthermore, there is some evidence to suggest that 
the probability of transition across regimes is itself a function of short-term interest rate differentials. Failure to account for either regime switching and/or dependence on short-term interest rate differentials may lead to invalid inference, biased forecasts and consequently inefficient risk management as Value-at-Risk $(V a R)$ measures or volatility estimates for option pricing may be biased.

This paper contains five sections. The next section outlines the Markov Switching EGARCH model of stock returns. The third section describes the data. Section four reports the empirical results and is divided into three subsections. The first subsection outlines the results associated with the baseline models of equity return. The second and third subsections outline the results for the extended Markov Switching EGARCH models with fixed and time varying transition probabilities, respectively. The final section provides a summary and some concluding comments.

\section{The Markov Switching EGARCH Model}

There is a substantial literature describing the volatility of stock returns and, in particular, the asymmetry in stock volatility ${ }^{2}$. Following a negative shock to equity prices, equity returns tend to display more volatility than would occur following a positive shock of equal magnitude. Nelson (1991) presents the EGARCH model designed to capture such asymmetry. The $\operatorname{EGARCH}(1,1)$ may be written as

$$
\begin{aligned}
r_{t} & =\mu_{t}+\varepsilon_{t} \\
\varepsilon_{t} & \sim N\left(0, h_{t}\right) \\
\log \left(h_{t}\right) & =\omega+\alpha\left[\left|\frac{\varepsilon_{t-1}}{\sqrt{h_{t-1}}}\right|-\sqrt{2 / \pi}\right]+\beta \log \left(h_{t-1}\right)+\delta \frac{\varepsilon_{t-1}}{\sqrt{h_{t-1}}}
\end{aligned}
$$

The logarithmic construction of (1) ensures that the estimated conditional variance, $h_{t}$, is strictly positive avoiding the need for the non-negativity constraints used in the estimation of GARCH models. Moreover, since $\hat{\delta}$ is typically negative in sign, a negative innovation, $\varepsilon_{t}<0$, generates more volatility than a positive innovation of equal magnitude. The innovation $\varepsilon_{t}$ may be treated as a collective measure of news about equity prices arriving to the market over the period $t-1$ to $t$. Suppose information is held constant at

\footnotetext{
${ }^{2}$ This asymmetry is commonly referred to as the leverage effect after Black (1976) and Christie (1980) who argue that that the increased leverage implied by a decline in stock prices results in higher equity volatility. An alternative explanation of asymmetry in equity volatility is referred to as the volatility feedback hypothesis; if volatility is persistent any increase in current volatility will, by definition, raise future volatility and thus lead to price falls in markets that price volatility. The fall in current equity prices allows for an increase in the required return necessary to compensate investors for holding more volatile equity.
} 
time $t-2$ and before, Engle and $\mathrm{Ng}$ (1993) describe the relationship between $\varepsilon_{t-1}$ and $h_{t}$ as the news impact curve (NIC).The NIC for the $\operatorname{EGARCH}(1,1)$ may be written

$$
h_{t}= \begin{cases}A \cdot \exp \left[\frac{\delta+\alpha}{\sigma} \varepsilon_{t-1}\right] & \text { for } \varepsilon_{t-1}>0 \\ A \cdot \exp \left[\frac{\delta-\alpha}{\sigma} \varepsilon_{t-1}\right] & \text { for } \varepsilon_{t-1}<0\end{cases}
$$

where $A=\sigma^{2 \beta} \exp [\omega-\alpha \sqrt{2 / \pi}]$. Clearly given the construction of (2) $\delta<$ 0 will cause the slope of the NIC in the $\varepsilon_{t-1}<0$ segment to be steeper than corresponding slope in the $\varepsilon_{t-1}>0$ segment; volatility therefore responds asymmetrically to the sign of the shock. A major drawback of the GARCH approach is that single regime GARCH models are prone to overestimate the persistence of a shock in the face of an unparameterised change in regime, see Lamoureaux and Lastrapes (1990), Cai (1994) and Hamilton and Susmel (1994) inter alia.

Hamilton and Susmel (1994) and Cai (1994) develop the Markov switching ARCH or SWARCH model which has been widely applied to equity, interest rate and foreign exchange data. Gray (1995) develops a Markov switching GARCH model, hereafter MS-GARCH, which has been applied to interest rate and foreign exchange data. Deucker (1997) employs a similar model to investigate regime switching in US equity returns. Bauwens et al (2006) present a Bayesian approach to estimating the symmetric Markov Switching GARCH $(1,1)$ model.

We employ a Markov switching EGARCH model, which, unlike the SWARCH and MS-GARCH models, guarantees that $h_{t}$ is positive by construction without the use of non-negativity constraints and captures asymmetry in volatility. Ideally one would choose to estimate a model of the type

$$
\begin{aligned}
r_{t} & =\mu_{i t}+\varepsilon_{t} \\
\varepsilon_{t} & \sim N\left(0, h_{i, t}\right) \\
\log \left(h_{i t}\right) & =\omega_{i}+\alpha_{i}\left[\left|\frac{\varepsilon_{t-1}}{\sqrt{h_{i, t-1}}}\right|-\sqrt{2 / \pi}\right]+\beta_{i} \log \left(h_{i, t-1}\right)+\delta_{i} \frac{\varepsilon_{t-1}}{\sqrt{h_{i, t-1}}} .
\end{aligned}
$$

We allow for two states, $i$, indexed by an unobserved latent variable $S_{t}$ which takes the value of 0 or 1 depending on the state of the markets. Following Hamilton (1989), $S_{t}$ is assumed to follow a two-state Markov process with a fixed transition probability matrix $P$, written as

$$
P=\left[\begin{array}{cc}
p^{00} & 1-p^{11} \\
1-p^{00} & p^{11}
\end{array}\right]
$$


where,

$$
\begin{aligned}
p^{00} & =P\left(S_{t}=0 \mid S_{t-1}=0\right) \\
1-p^{00} & =P\left(S_{t}=1 \mid S_{t-1}=0\right) \\
p^{11} & =P\left(S_{t}=1 \mid S_{t-1}=1\right) \\
1-p^{11} & =P\left(S_{t}=0 \mid S_{t-1}=1\right)
\end{aligned}
$$

Implicitly, $S_{t}$ depends on past realisations of $r$ and $S$ only through $S_{t-1}$. The transition probabilities are initially assumed to be constant and are specified as:

$$
p^{00}=\frac{\exp \left\{\theta_{0}\right\}}{1+\exp \left\{\theta_{0}\right\}} \text { and } p^{11}=\frac{\exp \left\{\gamma_{0}\right\}}{1+\exp \left\{\gamma_{0}\right\}}
$$

However, Cai (1994) and Hamilton and Susmel (1994) argue that MSGARCH models are intractable. They point out that maximum likelihood estimation is impossible because the conditional variance depends on the entire past history of the data in a MS-GARCH model.

Gray (1996) argues that it is possible to construct a measure of $h_{t}$ that is not path dependant. Recall that $h_{t}=E\left[r_{t}^{2} \mid \Omega_{t-1}\right]-E\left[r_{t} \mid \Omega_{t-1}\right]^{2}$ which yields

$$
h_{t}=p^{00}\left(\mu_{0 t}^{2}+h_{0 t}\right)+\left(1-p^{00}\right)\left(\mu_{1 t}^{2}+h_{1 t}\right)-\left[p^{00} \mu_{0 t}+\left(1-p^{00}\right) \mu_{1 t}\right]^{2} .
$$

The measure of the conditional variance provided by (7) is conditional on available information, but aggregated across regimes and provides a path independent model of volatility. In (7) each conditional variance depends on the regime alone, and not on the entire history of the process.

Using (7) in place of the lagged conditional variance in (3) yields

$$
\begin{aligned}
r_{t} & =\mu_{i t}+\varepsilon_{t} \\
\varepsilon_{t} & \sim N\left(0, h_{i, t}\right) \\
\log \left(h_{i t}\right) & =\omega_{i}+\alpha_{i}\left[\left|\frac{\varepsilon_{t}-1}{\sqrt{h_{t-1}}}\right|-\sqrt{2 / \pi}\right]+\beta_{i} \log \left(h_{t-1}\right)+\delta_{i} \frac{\varepsilon_{t}-1}{\sqrt{h_{t-1}}} \\
h_{t} & =p^{00}\left(\mu_{0 t}^{2}+h_{0 t}\right)+\left(1-p^{00}\right)\left(\mu_{1 t}^{2}+h_{1 t}\right)-\left[p^{00} \mu_{0 t}+\left(1-p^{00}\right) \mu_{1 t}\right]^{2} .
\end{aligned}
$$

Satisfaction of the restriction $\left|\beta_{i}\right|<1$ for all regimes $i$, rules out the possibility of explosive, or non-stationary volatility. The NIC for (8) may be written

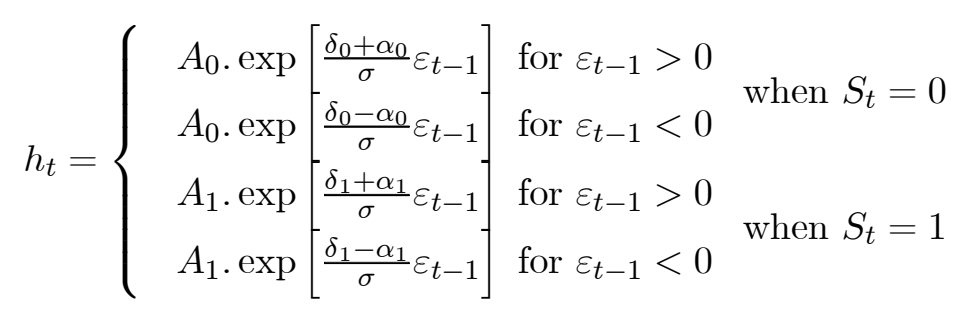


where $A_{i}=\sigma^{2 \beta_{i}} \exp \left[\omega_{i}-\alpha_{i} \sqrt{2 / \pi}\right]$. Clearly, $A_{i}$, the vertical intercept of the NIC will vary across regimes unless $\omega_{0}=\omega_{1}, \alpha_{0}=\alpha_{1}$ and $\beta_{0}=\beta_{1}$. Similarly, the degree of asymmetric response to news will be regime-dependent unless $\delta_{0}=\delta_{1}$.

Bae, Kim and Nelson (2007) estimate the regime switching threshold GARCH model

$$
h_{t}=\omega_{i}+\beta h_{t-1}+\alpha \varepsilon_{t-1}^{2}+\gamma \xi_{t-1}^{2}
$$

Where $\xi_{t}=\min \left\{0, \varepsilon_{t}\right\}$, is a threshold term capturing the asymmetric response of news to volatility. To ensure that $h_{t}$ is positive definite in (10) requires non-negativity constraints on the parameter vector $\theta=\left\{\omega_{0}, \omega_{1}, \alpha, \beta, \gamma\right\}$. To overcome the problem of path dependence, Bae et al (2007) only allow for switching in $\omega$ and where $\hat{\gamma}>0$ and $\hat{\beta}>0$, a persistent and asymmetric response to news. Essentially, the unconditional variance of return in regime $i$ in this approach is given by $\omega_{i} /(1-\alpha-\beta-\gamma / 2)$. However, neither the persistence nor the asymmetry of the response of volatility to news are state contingent by assumption. The NIC of (10) may be written as

$$
h_{t}=\left\{\begin{array}{cc}
A_{i}+\alpha \varepsilon_{t-1}^{2} & \text { if } \varepsilon_{t-1}>0 \\
A_{i}+(\alpha+\delta) \varepsilon_{t-1}^{2} & \text { if } \varepsilon_{t-1}<0
\end{array} \text { in regime } i=1,2 .\right.
$$

where $A_{i}=\omega_{i}+\beta \sigma^{2}$ for $i=1,2$. From (11) it is clear that the effect of regime switching is to cause the vertical intercept of the News Impact Curve of (10) to vary across regimes, but the shape of the NIC is constant across regimes

The Markov switching EGARCH (8) can be estimated using quasi maximum likelihood techniques, see Hamilton (1989) and Gray (1995), inter alia. To the best of the author's knowledge, this is the first time a Markov Switching Exponential GARCH model has been estimated. Furthermore unlike existing Markov Switching GARCH models, the model proposed in this paper has sufficient flexibility to capture regime dependence in the impact, persistence and asymetric response to a shock.

\section{Data Description}

Weekly data over the period $2^{\text {nd }}$ January 1980 to $29^{\text {th }}$ August 2007 were collected from Datastream. The equity returns were calculated as

$$
r_{t}=100 \times \log \left(I_{t} / I_{t-1}\right)
$$

where $I_{t}$ represents the value of the total return index, which captures both divided yields and capital gains. Also collected were interbank interest rates for loans of one day, one week, one, three and six months, and one year in maturity. ${ }^{3}$. Let $x_{m, t-1}$ represent an interest rate differential from the London

\footnotetext{
${ }^{3}$ The datstream codes are TOTMKUK for the equity returns. The iterbank interest rates collected were LDNIBON, LDNIB7D, LDNIB1M, LDNIB3M, LDNIB6M, LDNIB1Y
} 
Interbank Market. For loan maturity $m=1$ day, $x_{m, t}=i_{t, 1}^{L I B}-i_{t-1}^{L I B}$, and the one day measure captures changes in the overnight rate on the London Interbank market. For loans of greater than one day in maturity, $x_{m, t}=i_{t, m}^{L I B}-i_{t, 1}^{L I B}$, representing the spread over the interbank overnight rate.

\section{-Figure 1 about here-}

Visual inspection of the returns data, plotted in Figure 1, suggests that the returns are centered on $E\left(r_{t}\right)=0$. However, the volatility clustering common in asset returns is also evident in Figure 1. Irrespective of the sign of the return, large movements in $r_{t}$ tend to follow large movements, while small movements tend to follow small movements. Such volatility clustering is a common motivation for the use of GARCH models as conditional characterisations of asset returns.

\section{-Table 1 about here-}

Table 1 presents summary statistics for the returns, $r_{i t}$, and interest rate differentials, $x_{m, t}$. The evidence suggests that the data are non-normal in distribution. Interestingly, the degree of skewness in the interest rate differentials is monotonically increasing in $m$, while the kurtosis declines in $m$. The data all appear stationary, with the null hypothesis of a unit root of the Said and Dickey (1984) Augmented Dickey Fuller test being strongly rejected for all the series. There is evidence of ARCH in all the series, with the Engle (1982) LM test for the null of no ARCH of up to 10th order being strongly rejected for all the data.

\section{Results}

\subsection{The baseline models}

Table 2 presents results associated with the estimation of various baseline models of equity returns. The simplest model is a linear model of the type

$$
\begin{aligned}
\psi(L) r_{t} & =\mu+\varepsilon_{t} \\
\varepsilon_{t} & \sim N\left(0, \sigma^{2}\right)
\end{aligned}
$$

which we estimate by OLS.

In all cases considered below the autoregressive order, chosen using the Akaike (1974) and Hannan-Quinn (1979) information criteria, was determined to be zero. The model predicts a weekly average return of $0.2673 \%$, which implies a nominal annual return of approximately $13.9 \%$. However the standard deviation of return is $2.14 \%$ per week on average. While the residuals from (13) are free from serial correlation, there is very strong evidence of neglected $\mathrm{ARCH}$ in the data.

-Table 2 about here- 
There is a large literature discussing regime switching in equity returns.Turner, Startz and Nelson (1989), Deuker (1997), Lunde and Timmerman (2004), Bae, Kim and Nelson (2007) and Chen (2007) inter alia all report evidence of regime switching in equity returns from various markets. Many of these papers examine Markov-switching autoregressive models of the type

$$
\begin{aligned}
\psi(L) r_{t} & =\mu_{i}+\varepsilon_{t} \\
\varepsilon_{t} & \sim N\left(0, \sigma_{i}^{2}\right)
\end{aligned}
$$

This model is a special case of the Hamilton (1989) approach and describes the conditional distribution of $r_{t}$ as a mixture of normals, with mean $\mu_{i}$ and variance $\sigma_{i}^{2}$ in state $i$. Let $S_{t}$ be a variable taking the value $S_{t}=0$ when returns are drawn from an $N\left(\mu_{0}, \sigma_{0}^{2}\right)$ distribution. On the other hand $S_{t}=1$ when the data are drawn from an $N\left(\mu_{1}, \sigma_{1}^{2}\right)$ distribution. The unobserved state variable $S_{t}$ evolves according to (4), (5), and (6) above. When $S_{t}=0$ the trend in prices is $\mu_{0}$, while when $S_{t}=1$ the trend is $\mu_{1}$.

Quasi-maximum likelihood estimation results for the Markov switching AR model are presented in Table 2. Regime 1 corresponds to a high-mean, low-variance phase, while regime 2 corresponds to a low-mean, high-variance state, similar to the Bull and Bear Market phases reported by Chen (2007) inter alia. The estimated persistence for regime $i$ is $1 /\left(1-p^{i i}\right)$ for $i=0,1$. The high-mean low-variance regime has an estimated persistence of 68.49 weeks, while the low mean high variance regime has an estimated persistence of 9.56 weeks.

Does the Markov switching model provide a superior conditional characterisation of the data to the random walk model of returns? Testing the null of no switching in the data is a non-trivial task. Under such a null hypothesis $\mu_{0}=\mu_{1}$ and $\sigma_{0}^{2}=\sigma_{1}^{2}$. However any test will have a non-standard distribution since the transition probabilities are unidentified under the null, a feature known as the Davies' Problem (see Davies 1987). Furthermore there are problems associated with the maximum likelihood estimator under these restrictions since the derivative of the likelihood function with respect to $\mu_{0}$ and $\sigma_{0}^{2}$ is identically equal to zero. Garcia and Perron (1996) present a Likelihood Ratio test adopting the Davies (1987) upper bound approach. Defining $L_{0}$ as the value of the log-likelihood under the null and $L_{1}$ as the same measure under the alternative we obtain $L R=2\left(L_{1}-L_{0}\right)$. Assuming that the likelihood ratio has a single peak, an upper bound for the significance of $L R$ is given as $\operatorname{Pr}\left|\chi_{D}^{2}>L R\right|+2(L R / 2)^{D / 2} \exp (-L R / 2) / \Gamma(D / 2)$. Note that there are $D=2$ parameters appearing only under the alternative and that $\Gamma($.$) represents the gamma function. Obviously the upper bound$ is greater than $\operatorname{Pr}\left|\chi_{D}^{2}>L R\right|$, the usual marginal significance level associated with the LR test, in this case a $\chi^{2}(2)$ value of 5.99 assuming a $5 \%$ level of confidence. Garcia (1998) obtains critical values for the long-swings 
model using Monte-Carlo simulation, with the $95 \%$ critical value of 10.89 for the model considered here. The likelihood ratio statistic for the null of no switching is displayed as $L R_{1}$ in Table 3. The statistic far exceeds the $\chi^{2}(2)$, Garcia and Perron (1996) and Garcia (1998) critical values. This suggests that the Markov-Switching model may provide a superior conditional characterisation of the data than the linear model of returns. Table 2 also presents the results of a Wald test of the null hypothesis of no switching in the mean $W_{1}$ and no switching in the variance, $W_{2}$. Both these hypotheses are rejected for the data at all usual levels of confidence. There was no evidence of serial correlation in the standarised residuals of (14). However, there is strong evidence of neglected $\mathrm{ARCH}$ in the standardised residuals.

Column 3 of table 2 reports quasi maximum likelihood estimates of the EGARCH model (1). The standardised residuals of the model are free from serial correlation and neglected ARCH. The model is stationary given that $|\hat{\beta}|<0$ and predicts an average weekly return of $0.2829 \%$ corresponding to an annual return of $14.9 \%$ in nominal terms. Furthermore, given the negative and significant estimate of $\delta$, the EGARCH predicts an asymmetry in variance. Figure 2 presents the news impact curve for the estimated EGARCH model calculated using (2)

\section{-Figure 2 about here-}

The asymmetry in variance driven by $\hat{\delta}<0$, is clear in Figure 2. Negative shocks to return will, all else equal, produce higher levels of volatility than positive shocks of equal magnitude. The linear and Markov-Switching models are capable of capturing neither the the asymmetry in volatility, nor the volatility clustering, inherent in the returns data.

The final column of table 2 reports the estimates of the Markov-Switching EGARCH model described in (8) above. The estimates of $\theta_{0}$ and $\gamma_{0}$ are significant and imply that $p^{00}=0.9864$ and $p^{11}=0.8151$. The implied persistence of the high-mean, low-variance regime is 73.53 weeks. On the other hand, the low-mean, high variance regime is predicted to last 5.41 weeks on average. In the high-mean, low variance regime, the average return is estimated to be $0.3416 \%$ per week. In this regime, the estimate of the intercept in the conditional variance equation, $\omega_{0}$, is insignificantly different from zero. implying a relatively low level of unconditional volatility. Both $\alpha_{0}$, which captures the arrival of news in period $t$, and $\beta_{0}$ which captures persistence in the conditional volatility are significant while $\delta_{0}$ is insignificantly different from zero, although negative in sign. In the other regime the estimated return is $-0.6561 \%$ per week. In regime $1 \hat{\omega}_{1}=2.8868$, which is 22.9 times the magnitude of $\hat{\omega}_{0}$. Clearly regime 1 corresponds to a low-mean, high-variance regime. Interestingly, the magnitude of $\hat{\alpha}_{1}>\hat{\alpha}_{0}$ implying that any news arriving in regime 1 leads to relatively large increases in volatility as compared to regime 0 . However, as $\hat{\beta}_{1}$ is statistically insignificantly different from zero 
these shocks are not persistent. These results are somewhat similar to those reported by Friedman and Laibson (1989) for a sample of post-World War 2 US equity returns. Using a modified ARCH model that allows for jumps to divide their sample into ordinary and unusual price movements, Friedman and Laibson ( $i b i d$.) find that the volatility of ordinary returns displays persistence but that the volatilty associated with unusual or extraordinary price movements does not persist. Finally as $\hat{\delta}_{1}=-0.6351$, and is significantly different to zero for all usual levels of confidence, the market will react more sharply to negative innovations to returns than positive innovations of equal size.

The news impact curves for the MS-EGARCH model are displayed in figure 3

\section{-Figure 3 about here-}

The news impact curve for regime 0 is presented in the upper panel of figure 3. The degree of asymmetry in volatility is small, and the vertical intercept of the NIC is at $h_{0}=8.90$ approximately. Taken together this implies that in regime 0 , the unconditional level of volatility is relatively low, but any news $\varepsilon_{t-1} \neq 0$ will lead to increased volatility because $\left|\hat{\alpha}_{0}\right|>\left|\hat{\delta}_{0}\right|$. Consequently, in regime 0 the aphorism "no news is good news" appears to hold some truth.

However, in regime 1, the market displays a markedly different response to news. In the first case there is a significantly higher level of unconditional volatility. The vertical intercept of the NIC for regime 1 , displayed in the lower panel of figure 3 is at $h_{1}=27.2$, approximately. Given that $\hat{\alpha}_{1}<0$ and $\hat{\delta}_{1}<0$, the effect of a negative innovation $\varepsilon_{t-1}$ is to increase volatility

sharply in regime 1 . However as $\left|\hat{\alpha}_{1}\right|<\left|\hat{\delta}_{1}\right|$, when $\varepsilon_{t-1}>0$ volatility will decline. In the low mean-high variance regime bad news will tend to drive up volatility sharply, while good news will tend to be associated with declining volatility.

The upper and lower panels of figure 4 present the smoothed estimates of $p^{00}$ for the MS-AR and MS-EGARCH models, respectively.

\section{-Figure 4 about here-}

There is a great deal of similarity in the estimated probabilities of the high-mean, low variance regimes across the two models. The major difference between the two appears to arise in 1998 The MS-AR model suggests that the probability of the low-mean high variance regime was almost 1 , while the EGARCH suggests that the maximum probability of this regime was 0.4 approximately.

We compare the MS-EGARCH and EGARCH models using a $L R$ test. The $L R$ statistic was 76.3824, which is significantly in excess of 11.07 the the $95 \% \chi^{2}(5)$ variate. This is, at best, indicative since tests of $H_{0}: \mu_{0}=$ 
$\mu_{1}, \omega_{0}=\omega_{1}, \alpha_{0}=\alpha_{1}, \beta_{0}=\beta_{1}, \delta_{0}=\delta_{1}$ in (8) will have a non-standard distribution as the transition probabilities $p^{00}$ and $p^{11}$ are unidentified under the null hypothesis. To address this issue we calculate an upper bound on the $\chi^{2}(5)$ statistic, which assumes that the likelihood ratio has a single peak. The associated p-value is [0.0000] suggesting that the MS-EGARCH provides a superior characterisation of the data to the EGARCH.

\subsection{The Impact of Interbank Volatility: Constant Transition Probabilities}

Do events in the short term money markets impact upon equity returns? The interest rate differential $x_{1, t}=i_{t, 1}^{L I B}-i_{t-1}^{L I B}$, captures changes in the level of the yield curve for the London Interbank market. On the other hand, $x_{m, t}=i_{t, m}^{L I B}-i_{t, 1}^{L I B}$, for $m=7$ days, and 1,36 and 12 months, captures changes in the slope of the yield curve at each maturity.

Consider the extended Markov Switching EGARCH model:

$$
\begin{aligned}
r_{t} & =\mu_{i}+\phi_{i} x_{m, t-1}+\varepsilon_{t} \\
\varepsilon_{t} & \sim\left(0, h_{i, t}\right) \quad \text { for } i=0,1 \\
\log \left(h_{i t}\right) & =\omega_{i}+\alpha_{i}\left[\left|\frac{\varepsilon_{t-1}}{\sqrt{h_{t-1}}}\right|-\sqrt{2 / \pi}\right]+\beta_{i} \log \left(h_{t-1}\right)+\delta_{i} \frac{\varepsilon_{t-1}}{\sqrt{h_{t-1}}}+\lambda_{i} x_{m, t-1} \\
h_{t} & =p^{00}\left(\mu_{0 t}^{2}+h_{0 t}\right)+\left(1-p^{00}\right)\left(\mu_{1 t}^{2}+h_{1 t}\right)-\left[p^{00} \mu_{0 t}+\left(1-p^{00}\right) \mu_{1 t}\right]^{2} \\
p^{00} & =\operatorname{Pr}\left(S_{t}=0\right)=\frac{\exp \left\{\theta_{0}\right\}}{1+\exp \left\{\theta_{0}\right\}} \\
p^{11} & =\operatorname{Pr}\left(S_{t}=1\right)=\frac{\exp \left\{\gamma_{0}\right\}}{1+\exp \left\{\gamma_{0}\right\}}
\end{aligned}
$$

Holding the transition probabilities constant, there are two channels through which events in the interbank market may impact on the conditional distribution of equity returns. If the parameter estimates $\hat{\phi}_{i}$ are statistically significantly different from zero then the $m$ maturity interest rate differential impacts upon the conditional mean of the equity return. Consequently, rejection of the null hypothesis $H_{0}: \phi_{1}=\phi_{2}=0$ implies that $x_{m, t-1}$ will have some impact on the conditional mean of $r_{t}$. Furthermore, rejection of the hypothesis $H_{0}: \phi_{0}=\phi_{1}$ implies the relationship between interest rate differentials and equity returns varies across regimes.

Similarly, significance of $\hat{\lambda}_{i}$ implies that the $m$ maturity interest rate differential is a statistically significant determinant of the conditional variance of stock returns. Rejection of the null hypothesis $H_{0}: \lambda_{1}=\lambda_{2}=0$ implies that $x_{m, t-1}$ will have some impact on the conditional variance of $r_{t}$. Failure to reject the restriction $H_{0}: \lambda_{0}=\lambda_{1}$ would suggest that the relationship between the conditional variance of stock returns and interest rate differentials in the money market rates exhibits regime dependence. 
Table 3 presents quasi maximum likelihood estimates, diagnostic statistics and hypothesis test results for the extended MS-EGARCH model (15)

-Table 3 about here-

To briefly summarise the results, the overall behaviour across regimes and across maturities is similar to that reported in table 2. The estimates for regime 0 are consistent with a high-mean, low variance regime with persistent and symmetric response in volatility to news, $\varepsilon_{t-1}$. Regime 2 however, is a low-mean, high variance regime in which the response of volatility to news is asymmetric and lacks persistence.

Do events in the money market impact on the conditional mean of $r_{t}$ ? There is little evidence that $\phi_{i}$ is significant for any maturity considered. The data fails to reject a Wald test of the null hypothesis $H_{0}: \phi_{0}=\phi_{1}$, labelled as, $W_{2}$ for all maturities $m$. Similarly, there is no evidence that the data reject the hypothesis $H_{0}: \phi_{0}=\phi_{1}=0$. In short, there is no evidence that events in the money market influence the conditional mean of $r_{t}$ in a statistically significant fashion.

Turning to the conditional variance it is interesting to note that $\left|\hat{\lambda}_{1}\right|<$ $\left|\hat{\lambda}_{2}\right|$ for all maturities. For $m>1, \hat{\lambda}_{1}>0$ and $\hat{\lambda}_{2}<0$. At the one week and one month maturity, the null hypothesis $H_{0}: \lambda_{0}=\lambda_{1}=0$, is rejected. This implies that the one week and one month spread over the interbank rate influence the conditional variance of $r_{t}$ in a statistically significant fashion. Furthermore, the data fail to support the restriction $H_{0}: \lambda_{0}=\lambda_{1}$ indicating a regime specific response to $x_{m, t}=i_{m, t}^{L I B}-i_{1, t}^{L I B}$ for $m=$ one week and one month. There is strong evidence that the relationship between the conditional volatility of $r_{t}$ and interest differentials in the interbank market is state-contingent at shorter maturities. Furthermore a Wald test, $W_{5}$ of the restriction $H_{0}: \phi_{0}=\phi_{1}=\lambda_{0}=\lambda_{1}=0$ is rejected for $m=$ one week and one month. The restriction is satisfied for all other maturities considered.

\subsection{The Impact of Interbank Volatility, Time Varying Tran- sition Probabilities}

It is possible to relax the assumption of constant transition probabilities by allowing the transition matrix $P$ to depend on some variable $x_{m, t-1}$, yielding the time-varying transition matrix $P(t)$

$$
P(t)=\left[\begin{array}{cc}
p_{t}^{00}\left(x_{m, t-1}\right) & 1-p_{t}^{11}\left(x_{m, t-1}\right) \\
1-p_{t}^{00}\left(x_{m, t-1}\right) & p_{t}^{11}\left(x_{m, t-1}\right)
\end{array}\right]
$$

In this case $p_{t}^{i j}\left(x_{t-1}\right)=P\left(S_{t}=j \mid S_{t-1}=i, x_{m, t-1}\right)$. Movements across the regimes are governed by the time varying probability matrix $P(t)$. Any fluctuations in $x_{m, t}$ will lead the probabilities of a switch in regime to vary 
over time. By relaxing the assumption of fixed transition probabilities it is possible to investigate whether events in the money market influence not only the mean and variance of $r_{t}$, but also the probabilities of a change in regime.

Consider the unrestricted Markov Switching EGARCH model:

$$
\begin{aligned}
r_{t} & =\mu_{i}+\phi_{i} x_{m, t-1}+\varepsilon_{t} \\
\varepsilon_{t} & \sim\left(0, h_{i, t}\right) \quad \text { for } i=0,1 \\
\log \left(h_{i t}\right) & =\omega_{i}+\alpha_{i}\left[\left|\frac{\varepsilon_{t-1}}{\sqrt{h_{t-1}}}\right|-\sqrt{2 / \pi}\right]+\beta_{i} \log \left(h_{t-1}\right)+\delta_{i} \frac{\varepsilon_{t-1}}{\sqrt{h_{t-1}}}+\lambda_{i} x_{m, t-1} \\
h_{t} & =p^{00}\left(\mu_{0 t}^{2}+h_{0 t}\right)+\left(1-p^{00}\right)\left(\mu_{1 t}^{2}+h_{1 t}\right)-\left[p^{00} \mu_{0 t}+\left(1-p^{00}\right) \mu_{1 t}\right]^{2} \\
p_{t}^{00} & =\operatorname{Pr}\left(S_{t}=0\right)=\frac{\exp \left\{\theta_{0}+\theta_{1} x_{m, t-1}\right\}}{1+\exp \left\{\theta_{0}+\theta_{1} x_{m, t-1}\right\}} \\
p_{t}^{11} & =\operatorname{Pr}\left(S_{t}=1\right)=\frac{\exp \left\{\gamma_{0}+\gamma_{1} x_{m, t-1}\right\}}{1+\exp \left\{\gamma_{0}+\gamma_{1} x_{m, t-1}\right\}}
\end{aligned}
$$

As before, significance of $\phi_{i}$ and/or $\lambda_{i}$ indicates the conditional mean and/or conditional variance of $r_{t}$ responds in a possibly state contingent fashion to $x_{m, t}$.

Consider the parameterisation of the state transition probabilities

$$
p_{t}^{00}=\frac{\exp \left\{\theta_{0}+\theta_{1} x_{m, t-1}\right\}}{1+\exp \left\{\theta_{0}+\theta_{1} x_{m, t-1}\right\}} \text { and } p_{t}^{11}=\frac{\exp \left\{\gamma_{0}+\gamma_{1} x_{m, t-1}\right\}}{1+\exp \left\{\gamma_{0}+\gamma_{1} x_{m, t-1}\right\}}
$$

The use of the logistic functional form in (18) and (??), which constrains the transition probabilities into the interval $(0,1)$ was suggested by Filardo (1994).

It follows that

$$
\frac{\partial p_{t}^{00}}{\partial x_{m, t-1}}=\theta_{1} p_{t}^{00}\left(1-p_{t}^{00}\right), \text { and } \frac{\partial p_{t}^{11}}{\partial x_{m, t-1}}=\gamma_{1} p_{t}^{11}\left(1-p_{t}^{11}\right) .
$$

The transition probabilities $p_{t}^{00}$ and $p_{t}^{11}$ are non-negative and bounded between zero and unity in magnitude, implying that the signs of $\frac{\partial p_{t}^{00}}{\partial x_{m, t-1}}$ and $\frac{\partial p_{t}^{11}}{\partial x_{m, t-1}}$ are governed by the signs of $\hat{\theta}_{1}$ and $\hat{\gamma}_{1}$. For $\hat{\theta}_{1}>0$ a positive shock to $x_{m, t-1}$ implies that the equity returns are more likely to stay in regime 0 . Conversely, $\hat{\theta}_{1}<0$ implies that a switch to the high volatility state is more likely following a positive shock to $x_{m, t-1}$.

\section{-Table 4 about here-}

Table 4 presents quasi maximum likelihood estimates, diagnostic statistics and hypothesis test results for the unrestricted Markov Switching 
EGARCH model (17). Again, the results are consistent with 2 regimes in $r_{t}$, a high-mean, low-variance regime and a low-mean, high-variance regime. In the case of the one week and one month maturities, there is evidence of a statistically significant and regime dependent response of return volatility to events in the money market.

At the $10 \%$ level of confidence, the null hypothesis of constant transition probabilities, $H_{0}: \hat{\theta}_{1}=\hat{\gamma}_{1}=0$, is rejected for all maturities except the 1 month and 12 month maturities. This implies that there is statistically significant evidence of time variation in the transition probabilities.

For the overnight maturity, $\hat{\theta}_{1}>0$ and $\hat{\gamma}_{1}>0$, implying that the probability of staying in a particular regime is increasing in $\Delta x_{1 t}$. For the one week maturity $\hat{\theta}_{1}>0$ implying that a positive shock to $x_{m, t}=i_{m, t}^{L I B}-i_{1, t}^{L I B}$ increases the probability of staying in the high-mean low-variance regime, while a narrowing of the differential increases the probability of a transition across regimes. In the other regime as $x_{m, t}$ becomes increasingly positive, the probability of staying in the low return, high variance regime falls as $\hat{\gamma}_{1}<0$. Figures 5 and 6 plot the response of $p_{t}^{00}$ and $p_{t}^{11}$ to movements in $x_{1, t}$ and $x_{7, t}$.

\section{-Figures 5 and 6 about here-}

It is noticeable that the response of $p_{t}^{00}$ to movements in $x_{1, t}$ and $x_{7, t}$, plotted in the upper panel of Figures 5 and 6 , respectively is flat. A comparison of the magnitudes of $\hat{\theta}_{0}$ and $\hat{\theta}_{1}$ suggests that the economic significance of time variation in $p_{t}^{00}$ is small.

Conversely, the lower panel of figures 5 and 6 suggests that as conditions in the money market tighten, the probability of being in the low-mean, highvariance regime declines. In figure 5 it is clear that when $x_{1, t}=\Delta i_{1, t}^{L I B}>0$, the probability of remaining in the low-return, high variance regime increases. In other words, increases in short-term interest rates are associated with a significantly higher probability of regime 1 .

When $x_{m, t}<0$ then $i_{m, t}^{L I B}<i_{1, t}^{L I B}$, for $m>1$ day. In other words, when the interest rate spread is negative, then the money market yield curve is inverted. The lower panel of figure 6 suggests that when $x_{m, t}<0$ the probability of remaining in the low mean-high variance regime increases.

Inverted yield curves are usually a result of tight monetary policy and therefore are a signal of poor prospects for short term growth. As the yield curve inverts, the opportunity cost of investment increases, making investment in equity less attractive. Morevover, a negatively sloped yield curve will tend to render the use of short term borrowings to finance longterm lending unprofitable, impacting heavily on the performance of maturity transforming intermediaries.

Why are shorter maturity interest rate differentials so important? It may be that firms seeking funding in the very short-term money market do so because they are significantly liquidity constrained and are unable 
to access longer term funding. Such firms are very exposed to the risk that short term funding will be unavailable at any point where refinancing is necessary. When the yield curve is significantly inverted, firms which are maturity transforming intermediaries, borrowing short-term in relatively liquid markets and lending in long-term relatively illiquid securities, can run into difficultly very rapidly. In short, a business may become insolvent simply because it cannot access sufficient cash to finance its short term activities and not because it is unviable in the medium to long term.

\section{Summary and Conclusions}

This paper considers the impact of volatility in the London interbank market on equity returns using weekly data over the period January 1980 to August 2007.

The results suggest that equity returns display significant evidence of regime switching, with strong evidence of two regimes in the data. Our preferred model for equity returns is a Markov Switching Exponential GARCH model. One regime is consistent with a high mean low variance state, within which volatility responds persistently but symmetrically to news. This regime tends to be dominant and is estimated to persist for approximately 75 weeks on average. The other regime appears to be a low-mean, high variance state within which the variance of returns respond asymmetrically to news. However, in this regime shocks to volatility display little evidence of persistence. The estimated duration of this second regime is approximately 6 weeks.

Extending the Markov-Switching EGARCH model to allow for the a relationship between interest rate differentials and equity returns, we find evidence that fluctuations in interest rate differentials at shorter maturities play a significant role in determining both the volatility of returns and the probability of a transition across regimes.

In the low-mean, high-volatility regime the impact of an increase in short term interest rates or a steepening in the slope of an inverted money market yield curve will exacerbate the volatility of returns. It is precisely when conditions in the money market are tightest that firms who borrow in the short term markets to finance long-term investment will be least profitable and most exposed to the risk of being unable to obtain refinancing. Furthermore, there is some evidence that the probability of being in the low mean-high volatility regime increases as the short term interest rate increases and/or the yield curve in the money market becomes inverted.

Failure to account for these features may lead to biased and misleading inference in econometric models of asset prices. A more serious issue is the potential mispricing of risk in the equity markets. 


\section{References}

[1] Akaike, H. (1974), "A New Look at Statistical Model Identification", I.E.E.E Transactions on Automatic Control, AC-19, 716-723.

[2] Bae, J, C.-J. Kim and C.R. Nelson (2007) "Why Are Stock Returns and Volatility Negatively Correlated?" Journal of Empirical Finance, 14, 41-58.

[3] Bauwens, L., A. Preminger and J.V.K. Rombouts (2006), "Regime Switching GARCH Models" CORE Discussion Paper, Number 2006/11

[4] Bera, A. and C. Jarque (1980), "Efficient Tests for Normality, Heteroscedasticity and Serial Independence of Regression Residuals", Economics Letters, 6, 255-259.

[5] Bernanke, B.S. and A.S. Blinder (1992) "The Federal Funds Rate and Channels of Monetary Transmission", American Economic Review, 82 (4) $901-921$.

[6] Bernanke, B.S. and K.N. Kuttner (2005) "What Explains the Stock Market's Reaction to Federal Reserve Policy", Journal of Finance, 60 (3) 1221-1251

[7] Black, F. (1976) "Studies of Stock Price Volatility Changes". Proceedings of the Meetings of the American Statistical Association: Business and Economics Division, 177-181.

[8] Bollerslev, T. and Wooldridge, J. (1992). "Quasi Maximum Likelihood Estimation and Inference in Dynamic Models with Time Varying Variances", Econometric Reviews, 11, 143-172.

[9] Cai, J., (1994), "A Markov Model of Unconditional Variance in ARCH", Journal of Business and Economic Statistics, 12, 309316.

[10] Campbell, J. and J. Ammer (1993) "What Moves the Stock and Bond Market?" Journal of Finance, 48, 3-37.

[11] Campbell, J. and R. Shiller (1988) "The Dividend-Price Ratio and Expectations of Future Dividends and Discount Factors", Review of Financial Studies, 1, 195-228.

[12] Chen, S.-S. (2007), "Does Monetary Policy Have Asymmetric Effects on Stock Returns?" Journal of Money, Credit and Banking, 39(2-3), 667-688.

[13] Christie, A. (1982) "The Stochastic Behaviour of Common Stock Variances: Value, Leverage and Interest rate Effects", Journal of Financial Economics, 10, 407-432. 
[14] Davies, R.B. (1987) "Hypothesis testing when a nuisance parameter is present only under the alternative", Biometrika, 64, 247-254.

[15] Dueker, M. (1997), Markov Switching GARCH Processes and Mean Reverting Stock Market Volatility," Journal of Business and Economics Statistics, 15(1), 26-34.

[16] Engle. R.F. (1982), "Autoregressive conditional heteroscedasticity with estimates of U.K. inflation". Econometrica, 50, 9871008.

[17] Engle, R. F., and V. K. Ng. (1993). "Measuring and Testing the Impact of News On Volatility", Journal of Finance, 48, 1749-1778.

[18] Filardo, A. (1994) "Business-Cycle Phases and Their Transitional Dynamics", Journal of Business and Economic Statistics, 12, 299-308.

[19] Friedman, B.M. and D.I. Laibson (1989), "Economic Implications of Extraordinary Movements in Stock Prices", Brookings Papers on Economic Activity, 2, 137-172.

[20] Garcia, R (1998), "Asymptotic Null Distribution of the Likelihood Ratio Test in Markov Switching Models", International Economic Review, 39(3), 763-88.

[21] Garcia, R. and P. Perron (1996) "An analysis of the real interest rate under regime shifts", Review of Economics and Statistics, 78, 111-125.

[22] Gordon, M.J. (1962) "The Investment, Financing and Valuation of the Corporation", Homewood, Illinois: Irwin.

[23] Glosten, L. R., R. Jagannathan, and D. E. Runkle. (1993). "On the Relationship Between the Expected Value and the Volatility of the Nominal Excess Return on Stocks", Journal of Finance, 48, 1779-1801.

[24] Gray, S.F., (1996) "Modeling the conditional distribution of interest rates as a regime-switching process", Journal of Financial Economics, $42,27-62$

[25] Hamilton, J.D. (1989), "A New Approach to the Economic Analysis of Nonstationary Time Series and the Business Cycle", Econometrica, 57, 357-384.

[26] Hamilton, J.D and R. Susmel (1994), "Autoregressive Conditional Heteroscedasticity and Changes in Regime, Journal of Econometrics, 64, 307-333

[27] Haas, M., S. Mittnik, and M. S. Paolella. (2004). "A New Approach to Markov-Switching GARCH Models", Journal of Financial Econometrics, 2, 493-530. 
[28] Hannan, E. J., and B. G. Quinn (1979): "The Determination of the Order of an Autoregression", Journal of the Royal Statistical Society, B, 41, 190-195.

[29] Jorion, P. (2000) "Risk Management Lessons from Long-Term Capital Management", European Financial Management, 6, 277-300.

[30] Klaassen, F. (2002) "Improving GARCH Volatility Forecasts with Regime Switching GARCH" Empirical Economics, 27, 363-394.

[31] Lamoureaux, C. and W. Lastrappes (1990) "Persistence in Variance, Structural Change and the GARCH Model", Journal of Business and Economic Statistics, 8, 225-234.

[32] Ljung, B and G.E.P. Box (1978) "On a Measure of Lack of Fit in Time Series Models", Biometrika 65(2):297-303

[33] Lunde, A. and A.G. Timmermann (2004), "Duration Dependence in Stock Prices: An Analysis of Bull and Bear Markets", Journal of Business and Economic Statistics, 22(3), 253-273.

[34] Nelson, D.B., (1991), "Conditional Heteroscedasticity in Asset Returns: A New Approach", Econometrica, 59,347-370.

[35] Pearce, D.K. and V.V. Roley (1985) "Stock Prices and Economic News", The Journal of Business, 58 (1), 49-67.

[36] Said E. and David A. Dickey (1984), 'Testing for Unit Roots in Autoregressive Moving Average Models of Unknown Order', Biometrika, 71, p 599-607

[37] Sellin, P. (2001) "Monetary Policy and the Stock Market: Theory and Empirical Evidence", Journal of Economic Surveys, 15, 491-541. 


\section{Tables and Figures}

Table 1: Data Description

\begin{tabular}{llllllll}
\hline \hline & $r_{t}$ & 1 Day & 1 Week & 1 Month & 3 Month & 6 Month & 12 Month \\
\hline Mean & 0.2672 & -0.0067 & 0.3578 & 0.4417 & 0.4890 & 0.4748 & 0.5083 \\
Variance & 4.5637 & 5.2700 & 3.1008 & 3.2896 & 3.4624 & 3.6774 & 4.0146 \\
Sk & -0.6601 & -0.0203 & -1.6313 & -1.7009 & -1.7431 & -1.8255 & -1.8994 \\
& {$[0.0000]$} & {$[0.7198]$} & {$[0.0000]$} & {$[0.0000]$} & {$[0.0000]$} & {$[0.0000]$} & {$[0.0000]$} \\
$E K$ & 7.0938 & 12.1691 & 21.8400 & 17.6815 & 16.6209 & 16.3997 & 15.4502 \\
& {$[0.0000]$} & {$[0.0000]$} & {$[0.0000]$} & {$[0.0000]$} & {$[0.0000]$} & {$[0.0000]$} & {$[0.0000]$} \\
$J-B$ & {$[0.0000]$} & {$[0.0000]$} & {$[0.0000]$} & {$[0.0000]$} & {$[0.0000]$} & {$[0.0000]$} & {$[0.0000]$} \\
$A D F(\mu)$ & -20.5178 & -23.4725 & -6.6292 & -6.5476 & -6.4091 & -6.1403 & -5.4818 \\
$A R C H(10)$ & 251.1796 & 40.8009 & 23.0073 & 28.2918 & 29.1388 & 27.9629 & 28.6623 \\
& {$[0.0000]$} & {$[0.0000]$} & {$[0.0107]$} & {$[0.0016]$} & {$[0.0016]$} & {$[0.0018]$} & {$[0.0014]$} \\
\hline \hline
\end{tabular}

Notes to Table 1: $S k$ and $E K$ are measures of skewness and excess kurtosis, respectively. $J-B$ is a Jarque- Bera test for normality of the standardised residuals. $A D F(\mu)$ is an augmented Dickey-Fuller test where the test regression includes an intercept. The critical values for the ADF test are $-3.4347,-2.8633$ and -2.5678 for the $1 \%, 5 \%$ and $10 \%$ levels of confidence, respectively. $A R C H(10)$ is Engles (1982) LM test for up to 10th order ARCH which is distributed as $\chi^{2}(10)$ under the null of no $A R C H$. Marginal significance levels displayed as [.]. 
Table 2: The Baseline Models

\begin{tabular}{|c|c|c|c|c|}
\hline \multicolumn{5}{|c|}{$\begin{array}{c}\text { Linear: } r_{t}=\mu+\varepsilon_{t} ; \quad \varepsilon_{t} \sim N\left(0, \sigma^{2}\right) \\
\text { MS-AR: } r_{t}=\mu_{i}+\varepsilon_{t} ; \quad \varepsilon_{t} \sim\left(0, \sigma_{i}^{2}\right) \\
\text { EGARCH: } r_{t}=\mu_{+}+\varepsilon_{t} ; \quad \varepsilon_{t} \sim N\left(0, h_{t}\right)\end{array}$} \\
\hline \multicolumn{2}{|c|}{$\log \left(h_{t}\right)=\omega+\alpha[$} & $\frac{\varepsilon_{t-1}}{\sqrt{h_{t-1}}} \mid-\sqrt{2 / \pi}$ & \multicolumn{2}{|c|}{$+\beta \log \left(h_{t-1}\right)+\delta \frac{\varepsilon_{t-1}}{\sqrt{h_{t-1}}}$} \\
\hline \multicolumn{5}{|c|}{ MS-EGARCH: $r_{t}=\mu_{i}+\varepsilon_{t} ; \quad \varepsilon_{t} \sim\left(0, h_{i, t}\right) \quad$ for $i=0,1$} \\
\hline \multicolumn{2}{|c|}{$\log \left(h_{i t}\right)=\omega_{i}+\alpha_{i}$} & $\frac{t-1}{h_{t-1}} \mid-\sqrt{2 / \pi}$ & ]$+\beta_{i} \log (h$ & $\left.{ }_{t-1}\right)+\delta_{i} \frac{\varepsilon_{t}-1}{\sqrt{h_{t-1}}}$ \\
\hline$h_{t}=p^{00}\left(\mu_{0}^{2}\right.$ & $\left.+h_{0 t}\right)+(1$ & $\left.-p^{00}\right)\left(\mu_{1 t}^{2}+h\right.$ & $\left.h_{1 t}\right)-\left[p^{00} \mu\right.$ & $\left.+\left(1-p^{00}\right) \mu_{1 t}\right]$ \\
\hline & "Linear & "MS-AR & "EGARCH & "MS-EGARCH \\
\hline$\mu_{0}$ & $\begin{array}{l}0.2673 \\
(0.0562)\end{array}$ & $\begin{array}{l}0.3517 \\
(0.0503)\end{array}$ & $\begin{array}{l}0.2829 \\
(0.0502)\end{array}$ & $\begin{array}{l}0.3416 \\
(0.0499)\end{array}$ \\
\hline$\mu_{1}$ & & $\begin{array}{l}-0.3516 \\
(0.3266)\end{array}$ & & $\begin{array}{l}-0.6561 \\
(0.3096)\end{array}$ \\
\hline$\left(\sigma_{0}^{2}\right) \quad \omega_{0}$ & $\begin{array}{l}4.5605 \\
(0.3615)\end{array}$ & $\begin{array}{l}2.8184 \\
(0.1323)\end{array}$ & $\begin{array}{l}-0.0483 \\
(0.0256)\end{array}$ & $\begin{array}{l}0.1313 \\
(0.1017)\end{array}$ \\
\hline$\left(\sigma_{1}^{2}\right) \quad \omega_{1}$ & & $\begin{array}{l}16.8897 \\
(1.4199)\end{array}$ & & $\begin{array}{l}2.8868 \\
(0.3444)\end{array}$ \\
\hline$\alpha_{0}$ & & & $\begin{array}{l}0.1885 \\
(0.0281)\end{array}$ & $\begin{array}{l}0.1841 \\
(0.0636)\end{array}$ \\
\hline$\alpha_{1}$ & & & & $\begin{array}{l}-0.4876 \\
(0.1769)\end{array}$ \\
\hline$\beta_{0}$ & & & $\begin{array}{l}0.9289 \\
(0.0134)\end{array}$ & $\begin{array}{l}0.6775 \\
(0.0796)\end{array}$ \\
\hline$\beta_{1}$ & & & & $\begin{array}{l}0.1296 \\
(0.1709)\end{array}$ \\
\hline$\delta_{0}$ & & & $\begin{array}{l}-0.1118 \\
(0.0164)\end{array}$ & $\begin{array}{l}-0.0336 \\
(0.0362)\end{array}$ \\
\hline$\delta_{1}$ & & & & $\begin{array}{l}-0.6351 \\
(0.1233)\end{array}$ \\
\hline$\theta_{0}$ & & $\begin{array}{l}4.2122 \\
(0.3512)\end{array}$ & & $\begin{array}{l}4.2804 \\
(0.4077)\end{array}$ \\
\hline$\gamma_{0}$ & & $\begin{array}{l}2.1471 \\
(0.3435)\end{array}$ & & $\begin{array}{l}1.4832 \\
(0.4077)\end{array}$ \\
\hline$p^{00}$ & & 0.9854 & & 0.9864 \\
\hline$p^{11}$ & & 0.8954 & & 0.8151 \\
\hline$L$ & -3144.5390 & -3015.4396 & -3029.4947 & -2991.3030 \\
\hline
\end{tabular}

Notes to table 2: $L$ is the value of the $\log$ likelihood function. Bollerslev-

Wooldridge standard errors displayed as (.) 
Table 2 continued: Diagnostic Statistics

\begin{tabular}{lllll}
\hline \hline & Linear & MS-AR & EGARCH & MS-EGARCH \\
$Q(10)$ & {$[0.0951]$} & {$[0.2845]$} & {$[0.7079]$} & {$[0.6396]$} \\
$Q^{2}(10)$ & {$[0.0000]$} & {$[0.0000]$} & {$[0.8782]$} & {$[0.8736]$} \\
$J-B$ & {$[0.0000]$} & {$[0.0000]$} & {$[0.0000]$} & {$[0.0000]$} \\
$L R_{1}$ & & 258.1988 & & 76.3834 \\
& & $\{0.0000\}$ & & $\{0.0000\}$ \\
$W_{1}$ & & 4.4217 & & 9.3868 \\
& & {$[0.0355]$} & & {$[0.0022]$} \\
$W_{2}$ & & 100.2704 & 138.2059 \\
& & {$[0.0000]$} & & {$[0.0000]$} \\
\hline \hline
\end{tabular}

Notes to Table 2: $Q(10)$ and $Q^{2}(10)$ are Ljung-Box tests for serial correlation in the standardised residuals and their corresponding squares, respectively. Bollerslev-Wooldridge (1992) standard are errors displayed as (.). $J-B$ is a Jarque- Bera test for normality of the standardised residuals. $L R_{1}$ is a likelihood ratio test of the null of no switching in the MS-AR and MS-EGARCH models. Marginal significance levels calculated using the Davies (1987) upper bound approach displayed as $\{.\} . W_{1}$ is a Wald test of the null hypothesis of constant mean $H_{0}: \mu_{0}=\mu_{1}$, distributed as $\chi^{2}(1)$. $W_{2}$ is a Wald test of null hypothesis of constant variance $H_{0}: \sigma_{0}^{2}=\sigma_{1}^{2}$, distributed as $\chi^{2}(1)$ for the MSAR and $H_{0}: \omega_{0}=\omega_{1} ; \alpha_{0}=\alpha_{1} ; \beta_{0}=$ $\beta_{1} ; \delta_{0}=\delta_{1}$ distributed as $\chi^{2}(4)$ for the MSEGARCH. Marginal significance levels displayed as [.] . 
Table 3: Extended MS-EGARCH: Fixed Transition Probabilities

$$
\begin{aligned}
r_{t} & =\mu_{i}+\phi_{i} x_{j, t-1}+\varepsilon_{t} ; \quad \varepsilon_{t} \sim\left(0, h_{i, t}\right) \quad \text { for } i=0,1 \\
\log \left(h_{i t}\right) & =\omega_{i}+\alpha_{i}\left[\left|\frac{\varepsilon_{t}-1}{\sqrt{h_{t-1}}}\right|-\sqrt{2 / \pi}\right]+\beta_{i} \log \left(h_{t-1}\right)+\delta_{i} \frac{\varepsilon_{t}-1}{\sqrt{h_{t-1}}}+\lambda_{i} x_{j, t-1} \\
h_{t} & =p^{00}\left(\mu_{0 t}^{2}+h_{0 t}\right)+\left(1-p^{00}\right)\left(\mu_{1 t}^{2}+h_{1 t}\right)-\left[p^{00} \mu_{0 t}+\left(1-p^{00}\right) \mu_{1 t}\right]^{2} \\
p^{00} & =\operatorname{Pr}\left(S_{t}=0\right)=\frac{\exp \left\{\theta_{0}\right\}}{1+\exp \left\{\theta_{0}\right\}} \\
p^{11} & =\operatorname{Pr}\left(S_{t}=1\right)=\frac{\exp \left\{\gamma_{0}\right\}}{1+\exp \left\{\gamma_{0}\right\}} \\
x_{1, t} & =i_{1, t}^{L I B}-i_{1, t-1}^{L I B}, x_{m, t}=i_{m, t}^{L I B}-i_{1, t}^{L I B} \text { for } m=1 \text { week, } 1,3,6 \text {, and } 12 \text { months }
\end{aligned}
$$

\begin{tabular}{lllllll}
\hline \hline$x_{m, t}$ & 1 Day & 1 Week & 1 Month & 3 Months & 6 Months & 12 Months \\
\hline \hline$\mu_{0}$ & 0.3179 & 0.2877 & 0.3191 & 0.3243 & 0.3327 & 0.3425 \\
& $(0.0503)$ & $(0.0487)$ & $(0.0493)$ & $(0.0507)$ & $(0.0507)$ & $(0.0510)$ \\
$\mu_{1}$ & -0.6780 & -0.8131 & -0.8083 & -0.7022 & -0.7411 & -0.7694 \\
& $(0.3737)$ & $(0.7451)$ & $(0.3302)$ & $(0.3322)$ & $(0.3074)$ & $(0.2898)$ \\
$\phi_{0}$ & 0.0289 & -0.0033 & -0.0071 & -0.0238 & -0.0343 & -0.0437 \\
& $(0.0213)$ & $(0.0230)$ & $(0.0221)$ & $(0.0226)$ & $(0.0223)$ & $(0.0219)$ \\
$\phi_{1}$ & 0.0279 & -0.4390 & -0.2704 & -0.1052 & -0.1513 & -0.1535 \\
& $(0.0097)$ & $(0.6013)$ & $(0.3058)$ & $(0.2830)$ & $(0.2903)$ & $(0.2739)$ \\
$\omega_{0}$ & 0.1499 & -0.0028 & 0.0652 & 0.0924 & 0.1067 & 0.1230 \\
& $(0.1049)$ & $(0.0577)$ & $(0.0816)$ & $(0.0999)$ & $(0.1030)$ & $(0.1058)$ \\
$\omega_{1}$ & 2.8898 & 3.7701 & 2.7282 & 2.8801 & 2.8834 & 2.8627 \\
& $(0.3458)$ & $(0.5647)$ & $(0.3069)$ & $(0.3665)$ & $(0.3696)$ & $(0.3693)$ \\
$\alpha_{0}$ & 0.1777 & 0.1271 & 0.1275 & 0.1738 & 0.1731 & 0.1721 \\
& $(0.0653)$ & $(0.0540)$ & $(0.0604)$ & $(0.0643)$ & $(0.0648)$ & $(0.0654)$ \\
$\alpha_{1}$ & -0.4518 & -0.1100 & -0.4417 & -0.4619 & -0.4667 & 0.4758 \\
& $(0.1823)$ & $(0.1886)$ & $(0.1793)$ & $(0.1765)$ & $(0.1787)$ & $(0.1867)$ \\
$\beta_{0}$ & 0.6627 & 0.8466 & 0.7542 & 0.7037 & 0.6948 & 0.6849 \\
& $(0.0831)$ & $(0.0447)$ & $(0.0640)$ & $(0.0789)$ & $(0.0807)$ & $(0.0820)$ \\
$\beta_{1}$ & 0.1193 & -0.4022 & 0.1494 & 0.1200 & 0.1230 & 0.1376 \\
& $(0.1756)$ & $(0.3116)$ & $(0.1661)$ & $(0.1846)$ & $(0.1853)$ & $(0.1829)$ \\
$\delta_{0}$ & -0.0372 & -0.0731 & -0.0223 & -0.0300 & -0.0272 & -0.0268 \\
& $(0.0369)$ & $(0.0296)$ & $(0.0347)$ & $(0.0367)$ & $(0.0367)$ & $(0.0369)$ \\
$\delta_{1}$ & -0.6093 & -0.2844 & -0.6518 & -0.6172 & -0.6209 & -0.6316 \\
& $(0.1334)$ & $(0.1537)$ & $(0.1369)$ & $(0.1300)$ & $(0.0367)$ & $(0.1365)$ \\
$\lambda_{0}$ & 0.0068 & 0.0454 & 0.0438 & 0.0234 & 0.0152 & 0.0071 \\
& $(0.0202)$ & $(0.0147)$ & $(0.0167)$ & $(0.0178)$ & $(0.0166)$ & $(0.0151)$ \\
$\lambda_{1}$ & 0.0252 & -0.2371 & -0.1202 & -0.0322 & -0.0498 & -0.0622 \\
& $(0.0813)$ & $(0.0639)$ & $(0.0776)$ & $(0.1157)$ & $(0.1112)$ & $(0.1075)$ \\
\hline \hline & & & & & & \\
& & & & & & \\
& & &
\end{tabular}


Table 3: Continued

\begin{tabular}{lllllll}
\hline \hline$x_{m, t}$ & 1 Day & 1 Week & 1 Month & 3 Months & 6 Months & 12 Months \\
\hline \hline$\theta_{0}$ & 4.2647 & 4.8641 & 4.3164 & 4.2143 & 4.2095 & 4.2158 \\
& $(0.4047)$ & $(0.4516)$ & $(0.3744)$ & $(0.3940)$ & $(0.3906)$ & $(0.3932)$ \\
$\gamma_{0}$ & 1.5076 & 1.1276 & 1.4657 & 1.3699 & 1.3706 & 1.3833 \\
& $(0.4477)$ & $(0.5502)$ & $(0.4315)$ & $(0.4517)$ & $(0.4542)$ & $(0.4569)$ \\
$p^{00}$ & 0.9861 & 0.9923 & 0.9868 & 0.9854 & 0.9854 & 0.9854 \\
$p^{11}$ & 0.8151 & 0.7554 & 0.8124 & 0.7974 & 0.7975 & 0.7995 \\
Log L & -2990.2509 & -2985.9988 & -2988.2984 & -2989.7506 & -2989.4639 & -2988.7960 \\
\hline \hline \multicolumn{7}{c}{ Diagnostic Statistics } \\
\hline \multirow{2}{*}{$Q(10)$} & {$[0.6371]$} & {$[0.7764]$} & {$[0.7427]$} & {$[0.6855]$} & {$[0.6877]$} & {$[0.6719]$} \\
$Q^{2}(10)$ & {$[0.8554]$} & {$[0.9539]$} & {$[0.9399]$} & {$[0.8902]$} & {$[0.8847]$} & {$[0.8770]$} \\
$J-B$ & {$[0.0000]$} & {$[0.0000]$} & {$[0.0000]$} & {$[0.0000]$} & {$[0.0000]$} & {$[0.0000]$} \\
$W_{1}$ & 0.0001 & 0.5266 & 0.7351 & 0.0811 & 0.1589 & 0.1567 \\
& {$[0.9966]$} & {$[0.4680]$} & {$[0.3912]$} & {$[0.7758]$} & {$[0.6901]$} & {$[0.6922]$} \\
$W_{2}$ & 1.8807 & 0.5431 & 0.8995 & 1.3315 & 2.8439 & 4.6503 \\
& {$[0.3892]$} & {$[0.7622]$} & {$[0.6378]$} & {$[0.5139]$} & {$[0.2412]$} & {$[0.0978]$} \\
$W_{3}$ & 0.0510 & 17.6509 & 3.8927 & 0.2013 & 0.3139 & 0.3848 \\
& {$[0.8214]$} & {$[0.0000]$} & {$[0.0485]$} & {$[0.6466]$} & {$[0.5753]$} & {$[0.5350]$} \\
$W_{4}$ & 0.1890 & 20.9255 & 7.7511 & 1.7341 & 0.9028 & 0.4597 \\
& {$[0.9098]$} & {$[0.0000]$} & {$[0.0207]$} & {$[0.4202]$} & {$[0.6367]$} & {$[0.7947]$} \\
$W_{5}$ & 2.4043 & 24.7776 & 12.5121 & 3.3160 & 4.1984 & 5.7261 \\
& {$[0.6618]$} & {$[0.0001]$} & {$[0.0139]$} & {$[0.5064]$} & {$[0.3798]$} & {$[0.2206]$} \\
\hline \hline
\end{tabular}

Notes to Table 3: $L$ is the value of the $\log$ likelihood function. BollerslevWooldridge (1992) standard are errors displayed as (.) . $Q(10)$ and $Q^{2}(10)$ are Ljung-Box tests for serial correlation in the standardised residuals and their corresponding squares, respectively. $J-B$ is a Jarque- Bera test for normality of the standardised residuals. $W_{1}$ is a Wald test of null constant slope $H_{0}: \phi_{0}=\phi_{1}$, distributed as $\chi^{2}(1) . W_{2}$ is a Wald test of zero slopes $H_{0}: \phi_{0}=\phi_{1}=0$, distributed as $\chi^{2}(2) . W_{3}$ is a Wald test of null constant slope $H_{0}: \lambda_{0}=\lambda_{1}$, distributed as $\chi^{2}(1)$. $W_{4}$ is a Wald test of zero slopes $H_{0}: \lambda_{0}=\lambda_{1}=0$, distributed as $\chi^{2}(2)$. $W_{5}$ is a Wald test for the exclusion of $x_{j, t} H_{0}: \phi_{0}=\phi_{1}=\lambda_{0}=\lambda_{1}=0$, distributed as $\chi^{2}(4)$. Marginal significance levels are displayed as [.] . 
Table 4: Extended MS-EGARCH: Time Varying Transition Probabilities

$$
\begin{aligned}
r_{t} & =\mu_{i}+\phi_{i} x_{j, t-1}+\varepsilon_{t} ; \quad \varepsilon_{t} \sim\left(0, h_{i, t}\right) \quad \text { for } i=0,1 \\
\log \left(h_{i t}\right) & =\omega_{i}+\alpha_{i}\left[\left|\frac{\varepsilon_{t}-1}{\sqrt{h_{t-1}}}\right|-\sqrt{2 / \pi}\right]+\beta_{i} \log \left(h_{t-1}\right)+\delta_{i} \frac{\varepsilon_{t}-1}{\sqrt{h_{t-1}}}+\lambda_{i} x_{j, t-1} \\
h_{t} & =p^{00}\left(\mu_{0 t}^{2}+h_{0 t}\right)+\left(1-p^{00}\right)\left(\mu_{1 t}^{2}+h_{1 t}\right)-\left[p^{00} \mu_{0 t}+\left(1-p^{00}\right) \mu_{1 t}\right]^{2} \\
p_{t}^{00} & =\operatorname{Pr}\left(S_{t}=0\right)=\frac{\exp \left\{\theta_{0}+\theta_{1} x_{j, t-1}\right\}}{1+\exp \left\{\theta_{0}+\theta_{1} x_{j, t-1}\right\}} \\
p_{t}^{11} & =\operatorname{Pr}\left(S_{t}=1\right)=\frac{\exp \left\{\gamma_{0}+\gamma_{1} x_{j, t-1}\right\}}{1+\exp \left\{\gamma_{0}+\gamma_{1} x_{j, t-1}\right\}} \\
x_{1, t} & =i_{1, t}^{L I B}-i_{1, t-1}^{L I B}, x_{m, t}=i_{m, t}^{L I B}-i_{1, t}^{L I B} \text { for } m=1 \text { week, } 1,3,6, \text { and } 12 \text { months }
\end{aligned}
$$

\begin{tabular}{lllllll}
\hline \hline$x_{m, t}$ & 1 Day & 1 Week & 1 Month & 3 Month & 6 Month & 12 Month \\
\hline \hline$\mu_{0}$ & 0.3090 & 0.3109 & 0.3060 & 0.2973 & 0.3024 & 0.3086 \\
& $(0.0498)$ & $(0.1954)$ & $(0.0494)$ & $(0.0506)$ & $(0.0506)$ & $(0.0501)$ \\
$\mu_{1}$ & -0.3202 & -0.6156 & -0.6015 & -0.0973 & -0.1818 & -0.3764 \\
& $(0.4386)$ & $(0.1954)$ & $(0.5600)$ & $(0.4462)$ & $(0.5085)$ & $(0.7003)$ \\
$\phi_{0}$ & 0.0266 & -0.0037 & -0.0097 & -0.0282 & -0.0343 & -0.0443 \\
& $(0.0220)$ & $(0.0248)$ & $(0.0217)$ & $(0.0233)$ & $(0.0221)$ & $(0.0211)$ \\
$\phi_{1}$ & 0.0305 & -0.0094 & -0.2745 & 0.0379 & -0.1268 & -0.2029 \\
& $(0.2743)$ & $(0.0212)$ & $(0.4830)$ & $(0.2981)$ & $(0.3902)$ & $(0.5156)$ \\
$\omega_{0}$ & 0.1141 & 0.0679 & 0.0049 & 0.0502 & 0.0186 & 0.0303 \\
& $(0.0980)$ & $(0.0722)$ & $(0.0656)$ & $(0.0899)$ & $(0.0846)$ & $(0.0887)$ \\
$\omega_{1}$ & 3.0940 & 2.7134 & 3.1950 & 3.1472 & 3.3017 & 3.5449 \\
& $(0.3517)$ & $(0.3410)$ & $(0.3971)$ & $(0.3857)$ & $(0.4320)$ & $(0.5556)$ \\
$\alpha_{0}$ & 0.1361 & 0.1982 & 0.0996 & 0.1028 & 0.1251 & 0.1619 \\
& $(0.0678)$ & $(0.0625)$ & $(0.0559)$ & $(0.0719)$ & $(0.0680)$ & $(0.0645)$ \\
$\alpha_{1}$ & -0.1729 & -0.5531 & -0.1084 & -0.0805 & -0.0931 & -0.1445 \\
& $(0.1525)$ & $(0.1389)$ & $(0.1757)$ & $(0.1635)$ & $(0.1671)$ & $(0.1760)$ \\
$\beta_{0}$ & 0.7059 & 0.7290 & 0.8342 & 0.7622 & 0.7907 & 0.7764 \\
& $(0.0800)$ & $(0.0555)$ & $(0.0514)$ & $(0.0714)$ & $(0.0644)$ & $(0.0691)$ \\
$\beta_{1}$ & -0.1142 & 0.2897 & -0.2016 & -0.1865 & -0.2318 & -0.2416 \\
& $(0.1796)$ & $(0.1549)$ & $(0.2231)$ & $(0.2048)$ & $(0.2329)$ & $(0.3077)$ \\
$\delta_{0}$ & -0.0593 & -0.0363 & -0.0562 & -0.0855 & -0.0749 & -0.0731 \\
& $(0.0375)$ & $(0.0362)$ & $(0.0319)$ & $(0.0390)$ & $(0.0371)$ & $(0.0351)$ \\
$\delta_{1}$ & -0.3647 & -0.6673 & -0.3302 & -0.2946 & -0.2950 & -0.3105 \\
& $(0.1089)$ & $(0.1054)$ & $(0.1292)$ & $(0.1162)$ & $(0.1223)$ & $(0.0877)$ \\
$\lambda_{0}$ & 0.0087 & 0.0283 & 0.0462 & 0.0195 & 0.0160 & 0.0112 \\
& $(0.0210)$ & $(0.0180)$ & $(0.0169)$ & $(0.0215)$ & $(0.0182)$ & $(0.0162)$ \\
$\lambda_{1}$ & 0.0958 & 0.3433 & -0.2176 & -0.0873 & -0.1087 & -0.0944 \\
& $(0.0775)$ & $(0.0989)$ & $(0.0663)$ & $(0.0952)$ & $(0.0975)$ & $(0.1256)$ \\
\hline \hline & & & & & & \\
& & & & & & \\
& & & & &
\end{tabular}


Table 4: Continued

\begin{tabular}{|c|c|c|c|c|c|c|}
\hline$x_{1, t}$ & 1 Day & 1 Week & 1 Month & 3 Month & 6 Month & 12 Month \\
\hline$\overline{\overline{\theta_{0}}}$ & $\begin{array}{l}4.3777 \\
(0.4138)\end{array}$ & $\begin{array}{l}4.4594 \\
(0.4387)\end{array}$ & $\begin{array}{l}4.6140 \\
(0.4402)\end{array}$ & $\begin{array}{l}4.3132 \\
(0.0215)\end{array}$ & $\begin{array}{l}4.3162 \\
(0.4474)\end{array}$ & $\begin{array}{l}4.2566 \\
(0.4303)\end{array}$ \\
\hline$\theta_{1}$ & $\begin{array}{l}0.2287 \\
(0.1050)\end{array}$ & $\begin{array}{l}0.1677 \\
(0.1129)\end{array}$ & $\begin{array}{l}-0.2546 \\
(0.1862)\end{array}$ & $\begin{array}{l}-0.6450 \\
(0.5178)\end{array}$ & $\begin{array}{l}-0.3524 \\
(0.1587)\end{array}$ & $\begin{array}{l}0.0427 \\
(0.3103)\end{array}$ \\
\hline$\gamma_{0}$ & $\begin{array}{l}1.9286 \\
(0.5447)\end{array}$ & $\begin{array}{l}1.4602 \\
(0.5610)\end{array}$ & $\begin{array}{l}1.5723 \\
(0.5018)\end{array}$ & $\begin{array}{l}1.6634 \\
(0.4758)\end{array}$ & $\begin{array}{l}1.4054 \\
(0.5010)\end{array}$ & $\begin{array}{l}0.9355 \\
(0.5649)\end{array}$ \\
\hline$\gamma_{1}$ & $\begin{array}{l}0.5864 \\
(0.4960)\end{array}$ & $\begin{array}{l}-0.8944 \\
(0.6087)\end{array}$ & $\begin{array}{l}-0.6611 \\
(0.6324)\end{array}$ & $\begin{array}{l}-0.4201 \\
(0.1584)\end{array}$ & $\begin{array}{l}-0.6622 \\
(0.6199)\end{array}$ & $\begin{array}{l}0.0102 \\
(0.2098)\end{array}$ \\
\hline $\log \mathrm{L}$ & -2987.0088 & -2983.4394 & -2985.5097 & -2987.2720 & -2987.5095 & -2987.907 \\
\hline \multicolumn{7}{|c|}{ Diagnostic Statistics } \\
\hline \multirow{5}{*}{$\begin{array}{l}Q(10) \\
Q^{2}(10) \\
J-B \\
W_{1}\end{array}$} & [0.6402] & {$[0.7434]$} & {$[0.7513]$} & {$[0.6314]$} & [0.6928] & {$[0.7170]$} \\
\hline & [0.9141] & [0.9129] & [0.9410] & {$[0.8966]$} & [0.8898] & {$[0.8836]$} \\
\hline & {$[0.0000]$} & {$[0.0000]$} & {$[0.0000]$} & {$[0.0000]$} & [0.0000] & {$[0.0000]$} \\
\hline & 0.0002 & 0.0294 & 0.3009 & 0.0575 & 0.0552 & 0.0940 \\
\hline & [0.9899] & [0.8639] & {$[0.5833]$} & [0.8274] & {$[0.8141]$} & {$[0.7591]$} \\
\hline \multirow{2}{*}{$W_{2}$} & 1.5114 & 0.2234 & 0.5051 & 1.4663 & 2.6521 & 4.7076 \\
\hline & {$[0.4697]$} & [0.8943] & {$[0.7768]$} & {$[0.4804]$} & {$[0.2655]$} & {$[0.0950]$} \\
\hline \multirow{2}{*}{$W_{3}$} & 1.2714 & 9.4521 & 13.7728 & 1.0316 & 1.3894 & 0.6499 \\
\hline & {$[0.2595]$} & {$[0.0021]$} & {$[0.0002]$} & [0.3097] & {$[0.2385]$} & {$[0.4201]$} \\
\hline \multirow{2}{*}{$W_{4}$} & 1.5842 & 15.9532 & 15.6997 & 1.2082 & 1.4830 & 0.8173 \\
\hline & {$[0.4529]$} & {$[0.0003]$} & {$[0.0004]$} & {$[0.5466]$} & {$[0.4764]$} & {$[0.6654]$} \\
\hline \multirow{2}{*}{$W_{5}$} & 4.9129 & 4.9782 & 2.1257 & 7.0726 & 4.9694 & 0.0129 \\
\hline & {$[0.0857]$} & {$[0.0830]$} & [0.3455] & [0.0291] & [0.0834] & [0.9904] \\
\hline \multirow{2}{*}{$W_{6}$} & 12.9864 & 21.9866 & 25.9946 & 14.6175 & 15.1692 & 7.0380 \\
\hline & [0.0433] & [0.0012] & [0.0002] & {$[0.0234]$} & [0.0190] & {$[0.3173]$} \\
\hline
\end{tabular}

Notes to Table 4: $L$ is the value of the $\log$ likelihood function. BollerslevWooldridge (1992) standard errors are displayed as (.) . $Q(10)$ and $Q^{2}(10)$ are Ljung-Box tests for serial correlation in the standardised residuals and their corresponding squares, respectively. $J-B$ is a Jarque- Bera test for normality of the standardised residuals. $W_{1}$ is a Wald test of null constant slope $H_{0}: \phi_{0}=\phi_{1}$, distributed as $\chi^{2}(1) . W_{2}$ is a Wald test of zero slopes $H_{0}: \phi_{0}=\phi_{1}=0$, distributed as $\chi^{2}(2) . W_{3}$ is a Wald test of null constant slope $H_{0}: \lambda_{0}=\lambda_{1}$, distributed as $\chi^{2}(1)$. $W_{4}$ is a Wald test of zero slopes $H_{0}: \lambda_{0}=\lambda_{1}=0$, distributed as $\chi^{2}(2)$. $W_{5}$ is a Wald test of zero slopes $H_{0}: \theta_{1}=\gamma_{1}=0$, distributed as $\chi^{2}(2) . W_{6}$ is a Wald test for the exclusion of $x_{j, t} H_{0}: \phi_{0}=\phi_{1}=\lambda_{0}=\lambda_{1}=\theta_{1}=\gamma_{1}=0$, distributed as $\chi^{2}(6)$. Marginal significance levels are displayed as [.] . 
FTSE Total Return

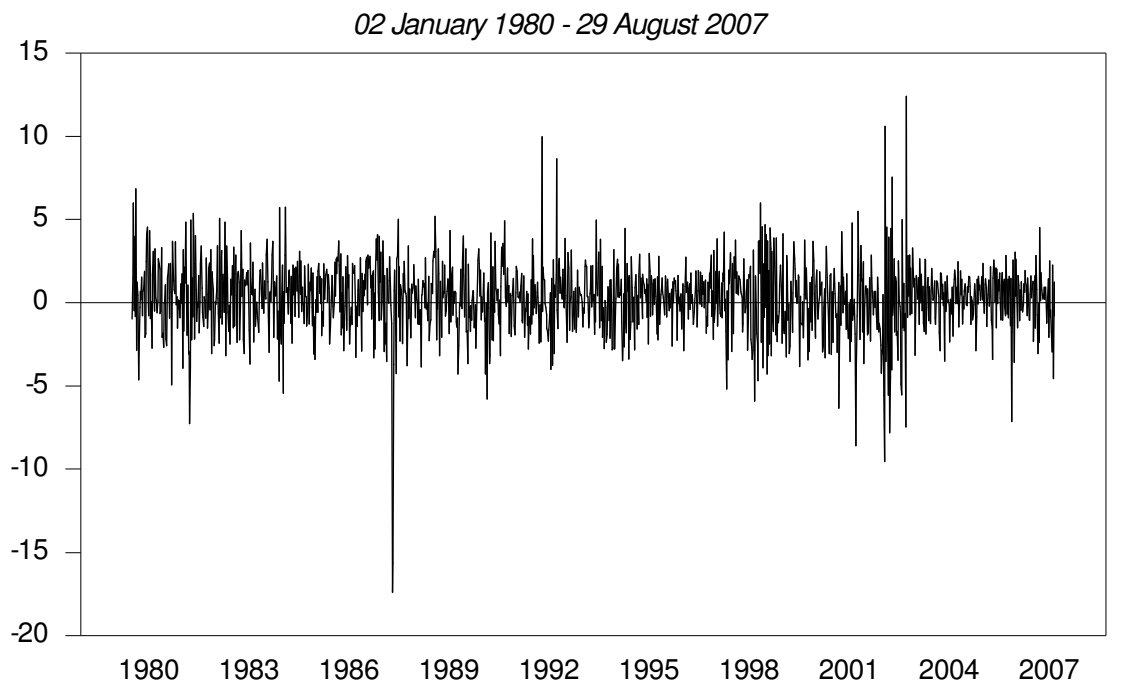

Figure 1: The continuously compounded total returns data $r_{t}$ 


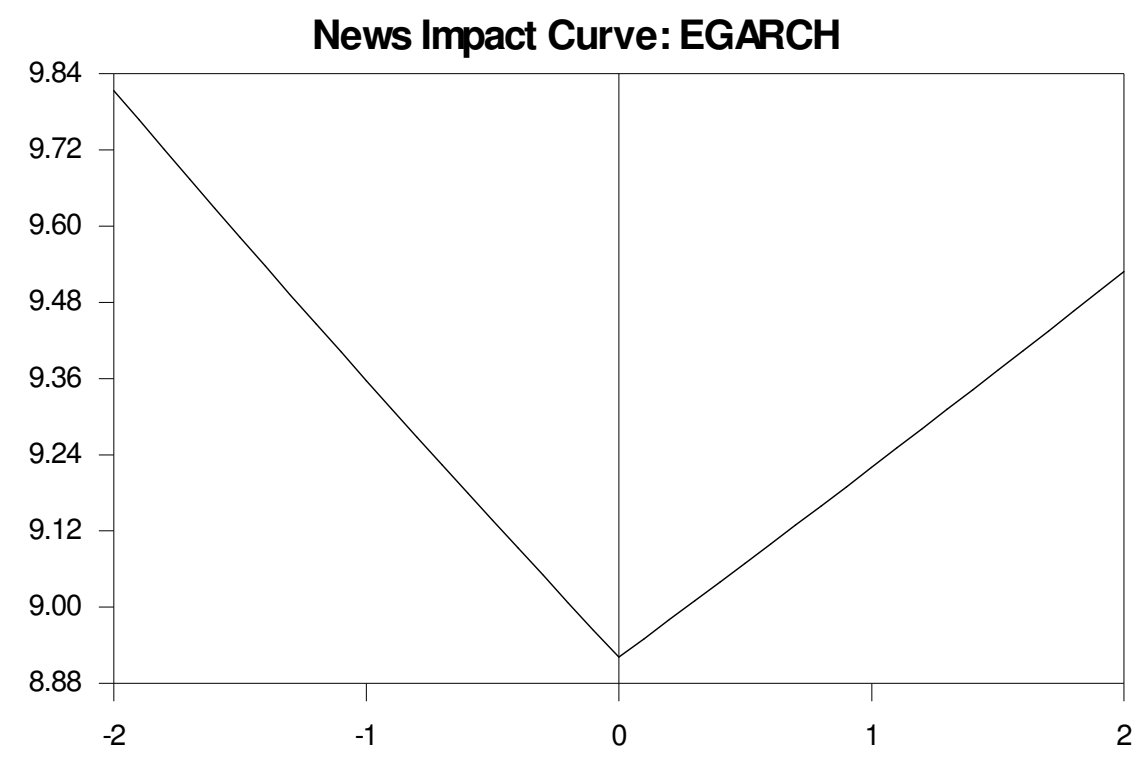

Figure 2: News Impact Curve - Single Regime EGARCH 

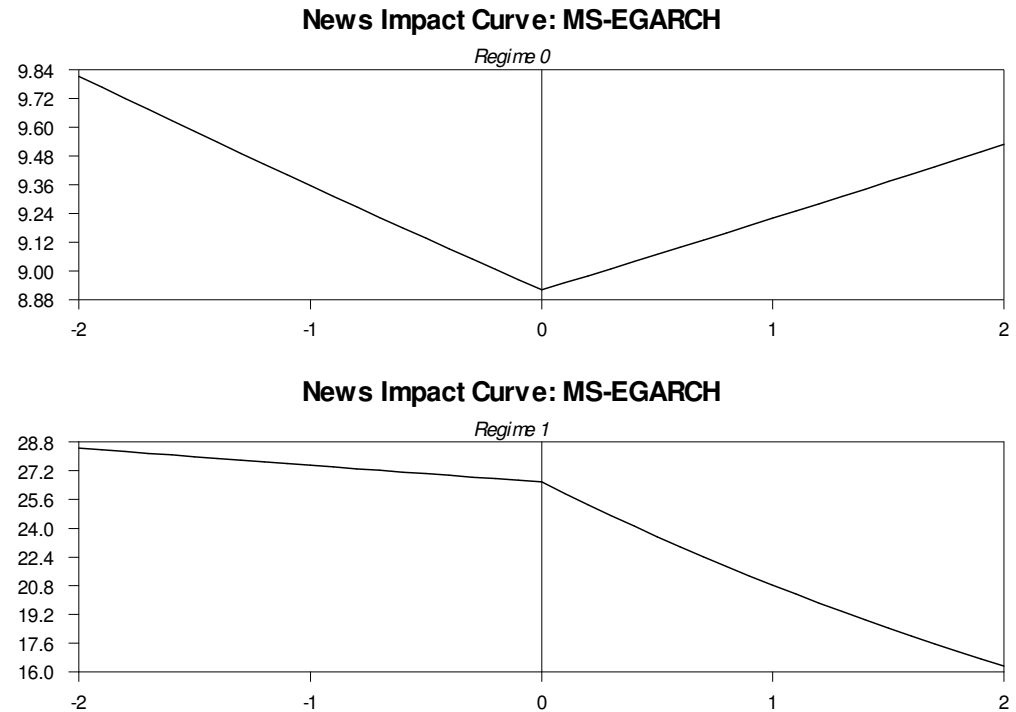

Figure 3: News Impact Curve: Markov Switching EGARCH - Constant Transition Probailities 


\section{Smoothed Transition Probability: Regime 0}

Total Retums
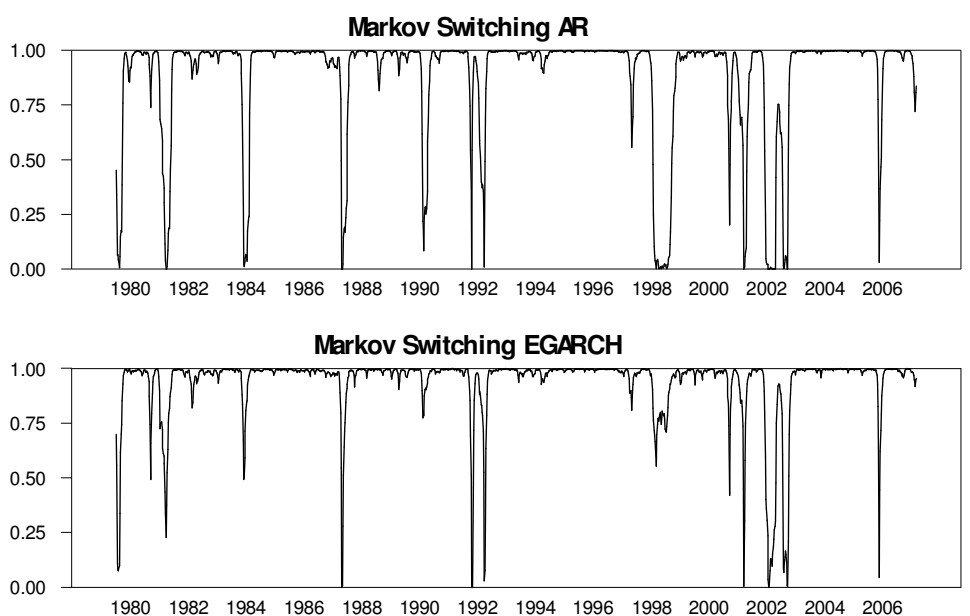

Figure 4: Smoothed $p^{00}$ constant transition probability models 

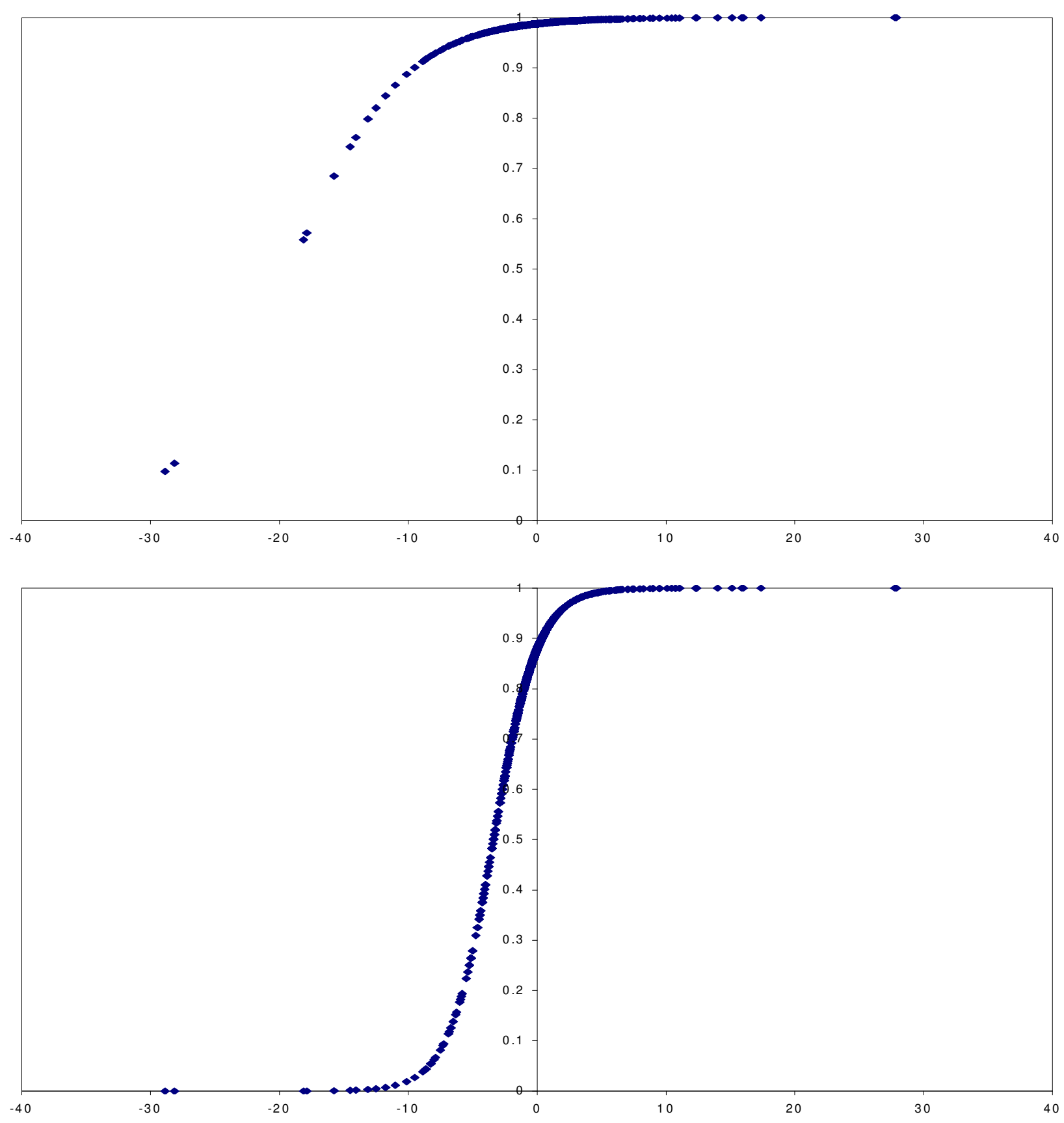

Figure 5: $p^{00}$ and $x_{1 t}$ (upper panel), $p^{11}$ and $x_{1 t}$ (lower panel), 


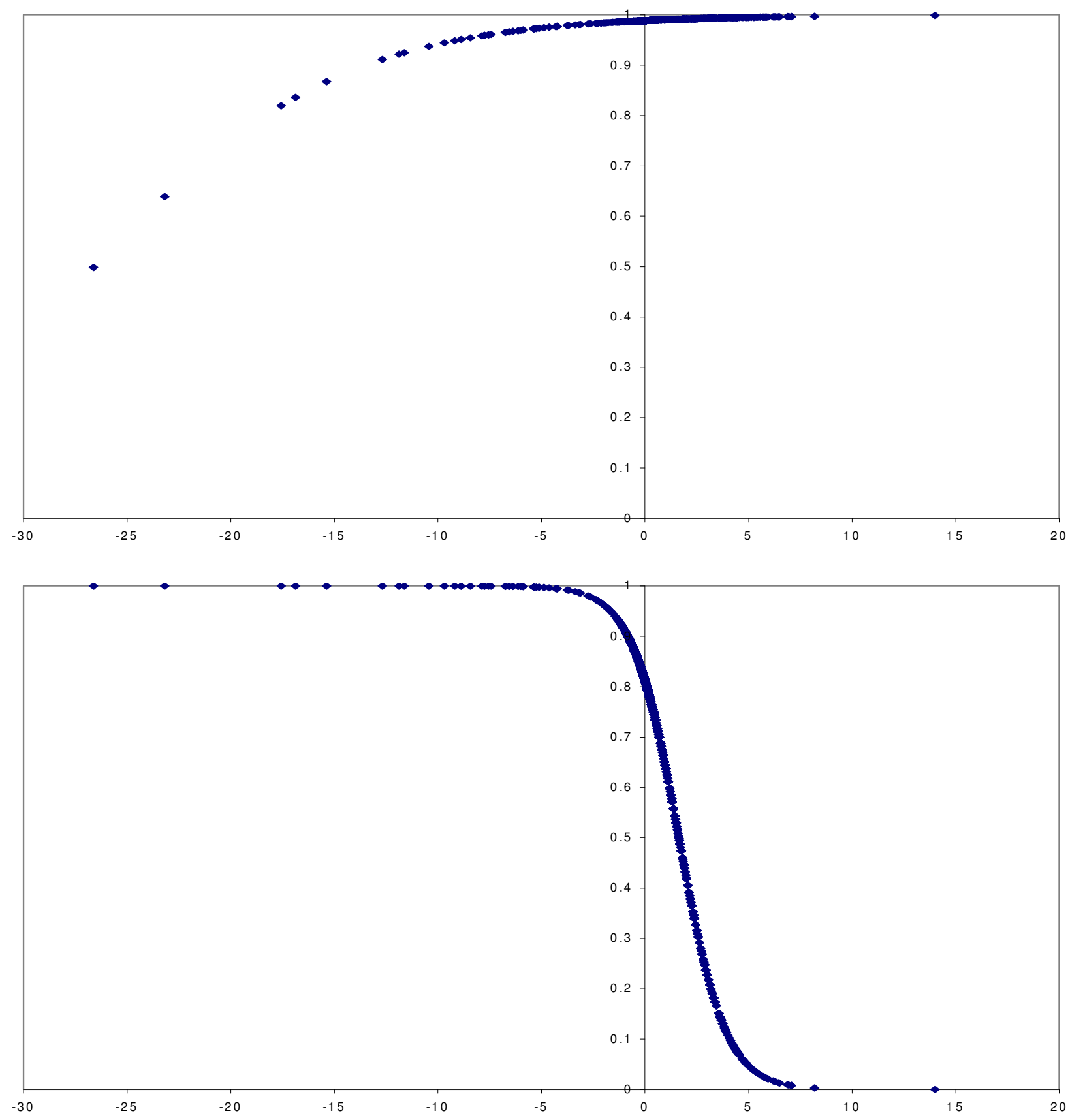

Figure 6: $p^{00}$ and $x_{7 t}$ (upper panel), $p^{11}$ and $x_{7 t}$ (lower panel), 